\title{
EL MUNDO DE LA PERCEPCIÓN
}

Autor: Maurice Merleau-Ponty. (2008)

Comentario: Carlos Lange V. ${ }^{1}$

El libro reseñado contiene siete conferencias realizadas por el filósofo francés Maurice MerleauPonty para su difusión por radio entre la población francesa entre octubre y noviembre del año 1948. Dichas conferencias fueron preparadas y realizadas con el objetivo de presentar y difundir de manera accesible y coloquial las claves del pensamiento francés de la época, tanto en el campo de la ciencia como de la filosofía. Es por esta razón que, rescatadas desde los archivos del Institut National de l' Audiovisuel (INA) francés en el año 2002 y editadas por el Fondo de Cultura Económica en el año 2003, estas siete conferencias exponen de manera clara, sucinta y amena los principios fundamentales de la fenomenología de la percepción desarrollada por el autor.

1 Chile. Licenciado en Antropología. Mg. en Desarrollo Urbano. Académico Instituto de la Vivienda, Facultad de Arquitectura y Urbanismo, Universidad de Chile.

Correo Electrónico: clange@uchile.cl.

revista invi № 67 / Noviembre 2009 / Volumen № 24: 181-183 181

Sin embargo, más allá del esnobismo que pudiera significar el retomar y citar la obra del mencionado autor, resulta fundamental cuestionarse respecto de la relevancia que el pensamiento de MerleauPonty pudiera tener en la actualidad.

En este sentido, y junto con destacar nuevamente el estilo simple, acotado y didáctico de esta publicación, ella presenta una síntesis acabada de la propuesta fenomenológica del autor, la cual tiene el mérito no menor de poner al sujeto en el centro de la concepción del espacio, desarrollando una perspectiva comprensiva de cómo éstos construyen su relación con él, de qué manera lo significan y qué rol juegan sus relaciones con otros sujetos en dicha significación. De esta manera, y sin preten- 
der reemplazar las propuestas desarrolladas en su clásica obra Fenomenología de la percepción publicada originalmente en 1945, el presente libro nos entrega cuatro claves respecto de los aportes que una perspectiva fenomenológica pudiera aportar para una mejor comprensión del espacio en la actualidad.

Un primer gran aporte de este texto es rescatar la importancia del mundo de la percepción y del mundo sensible en la construcción de nuestro conocimiento sobre el mundo. Muchas veces ignorado por el pensamiento científico, principalmente a partir de la influencia desarrollada sobre éste por el racionalismo cartesiano, la propuesta de Merleau-Ponty rescata aquel conocimiento sensible que nos pueden entregar el arte y la filosofía, y que permiten rescatar el valor de lo humano dentro de nuestras actuales concepciones del espacio.

Asociado al anterior, un segundo aporte de esta obra radica en el profundo cuestionamiento a la concepción de la geometría euclidiana respecto de la existencia de un espacio homogéneo, el cual se diferencia radicalmente del mundo físico. Desde la perspectiva fenomenológica de Merleau Ponty, el espacio no euclideano permite rescatar la concepción de un espacio heterogéneo donde la percepción que los hombres tienen de él y del medio físico que lo rodea es parte de su constitución. Desde esta perspectiva, el conocimiento humano se desarrolla a partir de la relación indisociable entre cuerpo y espíritu, premisa que permite establecer que las cosas con las cuales nos relacionamos adquieren atributos humanos en la medida que nos apoderamos de ellas y que no constituyen solamente objetos a los cuales podemos acceder exclusivamente a través de nuestra razón y del cual establezcamos un conocimiento soberano, sino más bien un conocimiento encarnado, un conocimiento vívido.

Un tercer aporte aparece relacionado con el reconocimiento realizado por el autor a la importancia fundamental que el cuerpo tiene para el conocimiento del mundo. Éste no constituye solamente un objeto que pueda ser tratado y explicado desde una perspectiva externa, sino que se revela como una condición permanente de la existencia, la cual permite tanto la apertura perceptiva al mundo como de la "creación" de ese mundo. Gracias al cuerpo la percepción presenta una dimensión activa y constitutiva del mundo, donde todo ser exterior sólo nos es accesible a través de nuestro cuerpo, revistiéndolo de atributos humanos que también hacen de él una mezcla de espíritu y cuerpo.

Por último, Merleau-Ponty pone especial acento en la concepción de los otros como habitantes y protagonistas fundamentales del espacio. En la medida que el cuerpo permite una apertura perceptiva al mundo y a la "creación" de ese mundo, los otros dejan de ser un simple objeto y se constituyen en semejantes partícipes del mismo mundo sensible, 
marcado por sus acciones, intenciones y propósitos, los cuales permiten comprender la figura moral de los otros.

En síntesis, la obra de Merleau-Ponty nos recuerda que rescatar la importancia y el protagonismo del hombre en la concepción que tenemos del espacio significa abordar un conjunto de complejidades e indefiniciones del cual el pensamiento científico y su afán reduccionista no siempre logran dar cuenta de manera certera. Tal y como nos recuerda el autor, "la existencia humana nunca puede hacer abstracción de sí para acceder a una verdad desnuda" (Merleau-Ponty, 2008: 72). 